\title{
17
}

\section{Pollution levels in local lakes in Denmark}

\author{
Norbert Steinhaus
}

\section{Context}

The Danish Society for the Conservation of Nature (DN) of Frederikssund is a local committee of a national NGO working towards protecting nature and the environment. DN Frederikssund addresses local issues regarding the protection of nature and the environment to achieve local sustainable development. It initiates local campaigns, participates in political hearings and comments on the municipality's environmental strategies and plans.

In the mid-1990s, DN Frederikssund became aware of science shops through correspondence from the science shops at Roskilde University Centre (RUC). DN Frederikssund saw this as an opportunity to engage in research about the pollution levels in village ponds in Frederikssund municipality.

Village ponds were polluted but DN Frederikssund lacked the scientific evidence to compel municipal authorities to take action. The organization did not have the capacity to do the research themselves so they requested help through the science shop at RUC. Specifically, they requested assistance from interested students to investigate the health of six village ponds and to make recommendations for improvement based on the results.

The practice of conducting research in partnership between local science shops and NGOs is a well-established tradition throughout much of Europe. According to the Living Knowledge Network:

Science Shops are ... small entities that carry out scientific research in a wide range of disciplines - usually free of charge and - on behalf of citizens and local civil society. The fact that Science Shops respond to civil society's needs for expertise and knowledge is a key element that distinguish them from other knowledge transfer mechanisms. Science Shops are often, but not always, linked to universities, where students conduct the research as part of their curriculum. (n.d.)

In February 2001, four students responded to the proposal; the project went until June 2001. For those students, the project satisfied two aims. First and foremost, it fulfilled an academic requirement that they complete a group project that included some experimental work. Second, it allowed them to conduct research that would be beneficial to a partner outside the university. The students were responsible for finding an academic supervisor to oversee the project for 
scientific rigour. A challenge for students engaged in research through a science shop is that often the client does not have an academic background, causing the students to spend a lot of time communicating their results for understanding and implementation.

The students' supervisor was initially sceptical because there was not a good working relationship between the Institute and the science shop, and because the supervisor felt the project 'lacked scientific interest'. However, he accepted the supervisory role because the students were motivated and engaged, and also he could see a future recruitment possibility.

The only expense to DN Frederikssund was transportation to RUC: the students paid both equipment and transportation expenses. Usually there is no budget for this kind of work, but the science shop does some cross-financing with money received for lectures and teaching. Total expenses were around 2,000 Danish kroner (approximately $\$ 180 \mathrm{CDN}$ ).

The project was facilitated by the RUC science shop, acting as an intermediary between the interested students and DN Frederikssund. The students and DN Frederikssund each approached the science shop directly. After the initial introduction, students worked directly with DN Frederikssund to develop the research questions.

This was the first time the parties had worked together. The science shop played a facilitative role between the students and the NGO. The students and the NGO met only twice - once to first establish contact, and on a second occasion to present the results and written report to the NGO. The students conducted the research with supervision from an academic supervisor at RUC. The supervisor did not meet with DN Frederikssund until the conclusion of the project.

An advantage by having projects done through the science shops was that the NGO does not have to take care of administration; this is the task of the science shop.

\section{Organization/structure}

During the first meeting between the partners, it was agreed what the research questions should be:

- Is it possible, through biomanipulation, to reach a sustainable situation of the water being clear in an eutrophic lake?

- Is it possible to reach a sustainable situation of clear water in Lille Rørbæk village pond through biomanipulation?

DN Frederikssund's original request included research on six village ponds but, during the first meeting between the students, the organization and the science shop, the students indicated they wanted to concentrate on only one village pond. Besides wanting to help the organization, it was very important for the students to obtain academic qualifications through the project. They felt that investigating more than one village pond would not give them the opportunity to conduct a sufficient level of the pond. 


\section{Activities}

The students reviewed relevant literature and scientific studies. They started a measuring programme on the pond. In addition, interviews were conducted with representatives from the NGO, the municipality and local residents. The NGO representative shared information with the students about the pond based on local stories and observation. The local residents also contributed to the project by sharing information about water levels or how the municipality's sewer system drained the village pond because of leakage. In turn, the students communicated project information to the local residents, leading some residents to offer boats and other services.

The research itself was not based on a participatory approach. Once the research questions were agreed upon, the students did testing and analysis without further formal involvement of the NGO. The students kept the NGO informed through email. The organization was satisfied with this level of involvement because they did not have the same expertise as students. Further, the students felt that if there had been more cooperation it could have had a negative effect on the learning process they were experiencing.

The way the students and DN Frederikssund chose to cooperate could be seen as a 'consultancy' agreement, in that the NGO had a problem for which they needed scientific documentation, and the students needed to do experimentbased research also beneficial for a user. Beyond this, ongoing cooperation and discussion were not prioritized by either. Further, this allayed the concerns of the students' supervisor, who requested that DN Frederikssund did not have influence on how the investigation was designed or carried out. The way this project was carried out indicates that ongoing dialogue and continued active involvement of the partner organizations throughout the research period are not preconditions for successful cooperation. Further decisions about what to include in the study were largely based on time and budgetary restrictions.

Originally, the students felt that DN Frederikssund did not know how much time and resources were required to document all the elements requested. But, the two groups reached an agreement on this, after which the students felt DN Frederikssund participated to the degree expected.

\section{Outcomes}

The research highlighted the pollution level in a village pond and how to rehabilitate it. The report did not assign responsibility for these efforts as the students deliberately chose not to report on this. They were only interested in the lake's biological processes and so left discussion of what should be done - by whom, the costs and timelines - to DN Frederikssund.

The NGO was able to use the results to pressure the municipality of Frederikssund on the issue of the lakes' health. This project was based on a direct need for documentation of a problem experienced by DN Frederikssund. The project has contributed to knowledge about an important local issue. 
This project has not resulted in any new policies as the municipality has not acted on the project's findings. However, this may be because of a limited effort to utilize the findings by the NGO. The report has been passed on to a biologist in the municipality, but to DN Frederikssund's knowledge, this person has no plans for rehabilitating the village ponds in the near future.

DN Frederikssund was very satisfied with the report because it felt the report was written in a way that enabled residents to understand the conclusions and recommendations, not just people with an academic background. DN Frederikssund has since defined more project requests for the science shops at RUC and the University of Copenhagen (KU).

The students are not aware how the DN Frederikssund has used the report's results; after they presented the report, they had no further contact with the organization. The students have not used the results from the project for other work. However, they have used methods they learned. Further, the supervisor has hired one of the students as an assistant and recruited two students to do their master's theses.

Copies of the report were also sent to local newspapers. During the research period, the organization also sent out press releases, explaining why they had required help from scientists.

Few projects brought to the science shop are science based. Thus, there are fewer opportunities for students in such programmes to engage in this type of research. Often, too, the scientific level of the projects requested through the science shop does not provide an opportunity for development of new scientific knowledge as they are based on practical problems. Those interviewed further argued that the projects, provided through the science shop at RUC, while aimed at students in the natural sciences, are more suited for engineering students because of the focus on solutions to practical problems. In this case, by instructing the students only to investigate one of six village ponds DN Frederikssund chose, the supervisor sought to improve the scientific interest in the project. As a result, the students gained more in-depth knowledge about the biological processes and the sampling and analysis methods needed for this kind of investigation.

But the RUC science shop does not aim to establish new research or teaching areas within the university. Participation in development of new research areas has never been a strategy for this science shop, and this may be one of the reasons why institutes, such as the Natural Science Institute, feel the science shop projects at RUC lack scientific content.

The students experienced pressure from their supervisor to not become 'a tool in a political play' as this had been seen in earlier projects. It was felt that, in some cases, insufficient research had been used in a political debate. To address this, the students explained to the NGO that they did not want to participate in the political debate or use the study to discuss who should be responsible for the quality of the water in the ponds, and why. They limited their undertaking to a scientific investigation of the conditions in the pond and recommendations on rehabilitation. DN Frederikssund accepted these requirements because their 
main objective was access to a scientific report addressing and clarifying the pollution level, which they could then bring forward to the municipality.

Despite the focus on producing scientific evidence in this case, one NGO representative noted that the style of communicating results from the university to civil society clients could be challenging. Students have to present the results in a certain way to comply with university rules; this style of presentation is often not appropriate for the needs of civil society clients.

Research completed through university structures are perceived by clients as impartial and can be used in a political debate to create legitimacy. Cooperation with intermediaries, such as science shops, further contributes to enhancement of knowledge within the civil society organizations and can help to develop new perspectives around specific issues.

When clients approach the science shops, they are asked to outline their request, specifying the problem and why there is a need for research in this area. Science shops play an important role in helping civil society clients formulate suitable research questions based on their organization's needs. In this case study, the client was able to formulate these on their own. However, as discussed previously, the research questions may need to be altered slightly in discussion with student researchers.

Sound scientific evidence was the most important desired outcome of the project. Accordingly, communication with, and active participation of, the NGO were not seen as important to this project. The students, however, quickly learned to cooperate with responsibilities and tasks, and were able to create a network, and gained the support of the local people. Participation in this project also gave students the opportunity to learn new research skills.

According to Helge B. Christensen, of DN Frederikssund, 'Access to research and knowledge through co-operation with the Science Shops are strengthening civil society organizations' ability to address local problems because a neutral investigation often is more powerful than an investigation performed by the individual organizations.' The perceived impartiality of research conducted through university structures via the science shop is seen as success. The NGO felt empowered through increased legitimacy in political debate, and felt the arguments were stronger than if they had produced the results themselves.

Both students and NGO representatives noted that communication of the results of the research is something that students need to think about throughout the research. DN Frederikssund wanted a scientific report to hand over to the municipality. So, in this case, it was important that the results were communicated scientifically.

DN Frederikssund took two actions with the research: it handed the report to the municipality, and it involved local newspapers in the hope of starting a debate about the future of the pond and the responsibilities of the municipality. Despite the documentation of the pond's pollution levels and the debate in local newspapers, the municipality has not initiated a dialogue with the NGO nor taken steps towards the pond's rehabilitation. Beyond providing the municipality with copies of the report, the NGO have not taken action to pressure the municipality. 
Nor has it used the articles in newspapers as a way of starting a debate with the general public.

The DN Frederikssund case shows that knowledge does not necessarily lead to influence. Influence is shaped by the support and participant constellations created around a topic. In this case, this did not happen with the local environmental administration. Even though Denmark has a tradition of strong environmental movements that feel empowered to challenge political structures and may use scientific evidence to do so, the country is not always successful in persuading participation.

The NGO chose not (directly or indirectly) to use the public arena as a forum for discussion, which indicates that, for this organization, cooperation with the responsible authorities is seen as the right way to reach its objectives, rather than pressuring through public debate.

This case shows that engagement of clients, the academic requirements on institutions and the frequency in shifts of NGO members all influence the process of knowledge production and can affect whether or not research leads to mutual knowledge production, or only to the enhancement of students' knowledge. Projects, facilitated through an intermediary such as the science shop, and based on cooperation with participants drawn from civil society, were seen as an interesting challenge that encouraged the development of students' communication and cooperation skills. It is also important to balance the needs of the clients while ensuring the project is sufficiently scientifically challenging. The draw of being able to participate in research with a practical use, and not simply 'a desktop study', was seen as important by both students and civil society clients.

The science shop concept, as an organization that acts as an intermediary between students and civil society organizations, is important to the development and capacity of civil society organizations. It is also important for researchers because, through interaction with civil society organizations, new research questions are developed and new perspectives explored.

- The relationship between university researchers and civil society organizations could be strengthened with more opportunities for direct interaction by, for example, setting up thematic networks or counselling committees made up of representatives from university institutes and civil society organizations.

- The relationship with students could be strengthened by involving the students' organizations, and/or students who already have performed projects through the science shops.

- University institutes should be involved in the process of defining requests from clients to the science shops. This would help to ensure an appropriate level of scientific challenge.

- Science shops need to be more visible both within and outside the university.

- Knowledge produced at universities often is not understandable to those outside the academy. Closer cooperation between university researchers, civil society organizations or private companies helps researchers to keep their 'feet on the ground', learn to speak an understandable language and 
produce knowledge that is applicable. Training for researchers and hands-on experience supports this process of mutual learning. This training (e.g., communication) can be done before or even during the study/research. This can help to address the alienation that is felt towards the type of knowledge produced at universities. 